\title{
European packaging industry foresight study_identifying global drivers and driven packaging industry implications of the global megatrends
}

\author{
Carl Olsmats • Jari Kaivo-oja
}

Received: 22 January 2014 / Accepted: 25 March 2014 / Published online: 10 April 2014

(C) The Author(s) 2014. This article is published with open access at Springerlink.com

\begin{abstract}
The purpose of the research is to provide a common multi-client platform as a base for further applied foresight work in the packaging sector. It aims to be a reference for a future-oriented strategic dialogue and a platform for strategic business development. The ambition with the research is not to provide an accurate forecast, but rather to initiate an improved preparedness for and active influence on future developments. This is done by mapping and analyzing general trends and drivers in society. The potential packaging implications of those trends and drivers are then evaluated to highlight potential future demands, opportunities and threats for packaging. Methods include participatory workshops/ focus groups with invited experts and users. Thus, this article provides results based on participatory foresight and Focus Group methodology. With a systematic and participatory process, a medium to long-term vision building is targeted to mobilize joint actions and influence current decision making.
\end{abstract}

Keywords Packaging industry · Competitive intelligence . Value networks · Participatory foresight $\cdot$ Strategic foresight . Megatrend analysis

\section{Introduction}

Understanding emerging megatrends and trends has always been a vital issue for industries, for value networks and for the clusters of various industry branches. This article is focused

C. Olsmats $(\square)$

Independent Managament Consultant, Stockholm, Sweden

e-mail: carl.olsmats@gmail.com

J. Kaivo-oja

Finland Futures Research Centre, Turku School of Economics,

University of Turku, Turku, Finland on one key industry in the world, the packaging industry. The methodology of this research is suitable for multi-client environments, where various industrial stakeholders work together and try to understand the logic of supply-chain networks and value networks of the future [2,4]. Thus, this approach is not a conventional corporate foresight approach, but serves broader value networks. From this standpoint, the article provides new perspectives to the fields of strategic and participatory foresight. Drivers of change are analyzed, and a broader discussion about driven and identified implications is presented. This approach provides new competitive intelligence for companies and corporations. The methodology is very close to the Driving Forces Analysis (DFA), one of the most used foresight methods in the field of company/corporate foresight [26-29]. The focus of this article is on foresight aspects; company-level strategic and value-network questions are left to other publications.

Conventional trend impact analysis [1] often focus on quantitative impacts. This article emphasizes the qualitative aspects and implications of megatrends instead. This kind of qualitative foresight approach is suitable when the futures of supply-chain and value networks are analyzed. For companies and corporations, identification of discontinuities, disruptive innovations, the need of creative accumulation and changes in path dependencies are vital strategy issues [3, 4]. This kind of foresight helps companies pay attention also to their dynamic capabilities. Thus, the approach can provide many competitive benefits for companies.

The origins of packaging date back to the early history of mankind. From the earliest times people have sought to preserve what they hunted and gathered. For this purpose our ancestors created earthenware and leather pouches to store their food. Packaging has evolved substantially since, along with the development of our civilization. Packaging today has a large impact on our society and plays a vital role in today's lifestyle of most consumers. Production, logistics and 
marketing systems performance and functionality are dependent on packaging. In the industry, materials are converted into packaging and distributed to serve in principle all business sectors dealing with physical products. The global packaging market is estimated to be worth around 560 Billion USD in 2009, whereof around one third in Europe [36]. The main end use sectors are food and beverage with around $50-60 \%$ of the total market, followed by health care and cosmetics. The main materials used for packaging are paper $\&$ board, plastics, metal, glass and wood.

From a business viewpoint the packaging system is becoming an increasingly vital and integrated factor for success in the marketplace. The influence of the packaging system is canalised through an efficient supply chain to add value and satisfy steadily increasing customer demands, described e.g. in the futures research [23].

Preparedness and a participatory process are key elements in foresight which not only researches the future, but also influences and shapes it through appropriate actions and strategies. The role model for research in this project was foresight work carried out at Packforsk in the late 90s [18-22, 31], where a forum for strategic and future-related issues for Packforsk, Packforsk's members and other partners and participants in the global packaging community was established. This was part of a strategic process to bring joint value to the participants, and to make a contribution in exploring and placing issues regarding the future at the top of the agenda for the packaging business. The intention was to support the industry and trade in strategic choices by providing key input parameters to business development processes. Identification and evaluation of driving forces and trends as well as an evaluation of their potential impacts on future packaging was a key area of the work.

The purpose of this research is to provide a common multi-client knowledge platform as a base for further applied foresight work on corporate and sub-sector levels in the packaging industry. It is a part of a larger foresight research effort carried out by Innventia in the years 2010 and 2011 [24], which has been continued in 2012 and 2013 [13]. It aims to be a reference for a future-oriented strategic dialogue and a platform for strategic business development. The ambition is not to provide an accurate forecast, but rather to initiate improved preparedness and active influence on future developments. This is done by mapping and analyzing general trends and drivers among consumers and businesses. Innovation aspects inside packaging industries are presented, as well as some aspects relevant for the consumer-driven innovation processes. The potential packaging implications of these trends and drivers are then evaluated to highlight potential future demands, opportunities and threats. It is intended to start building a multi-client platform for packaging foresight at corporate and sub-sector level in the project, but the use and possible applications of the platform are outside the boundary of this research paper.

The overall scope is global, looking into trends and drivers in a society and their potential implications for packaging. The main emphasis is however on Sweden and the EU.

\section{Methodology}

Figure 1 presents the methodological framework of the study, which consists of three basic pillars of foresight.

The three pillars are (1) Foresight methods, (2) actor networks and (3) decision-making process. This methodological framework is quite a typical foresight framework closely linked to "Fully-Fledged Foresight", including elements of planning, the use of futures methods, networking and foresight. Foresight is an activity which goes beyond academic or consultancy-based forecasts. The foresight process also includes complementing and informing decision-making and planning processes. The idea of foresight is to increase the effectiveness of methodology arsenal, networking processes and focused decision-making [9, p. 14].

Typically forward looking methods have to be combined and integrated as much as possible in the "strategic policy cycle" taking stock of appropriate structures for defining research agendas such as the technology platforms and multi-client platforms. In general, the challenge is to put together interoperable visions that can be exploited by decision-makers in multi-client organizations. In the optimal case, forward looking activities can help reinforce the longterm perspective in company culture and provide a greater role to cross-cutting issues inside the industry [see e.g. 15]. This article reports no business secrets, but key findings and reports of the foresight study are presented. The client companies used many tools of Business and Competitiveness Analysis (BCA) linked to the foresight study.

In essence, foresight provides a framework to think about, discuss and possibly also influence the future in a structured and constructive way. The main fields of foresight are strategic and participatory foresight. This research initiative includes both these aspects. The future could relate to e.g. packaging needs, R\&D and innovation priorities. Foresight provides a number of tools to support participants (i.e. decision makers, experts and other stakeholders) to develop visions of the future and pathways towards these visions. Typical methodological elements of foresight are: (1) diagnosis methods, (2) prognosis methods and (3) prescriptions [8]. Thus, foresight processes serve the need of strategic and visionary decisionmaking in companies and corporations [6, 29, 33].

In this study, diagnosis and prognosis are linked to the scenario approach. Scenarios are stories or storylines about the future. They are not attempts to predict the future; rather, 
Fig. 1 Methodological framework of the foresight study of the European Packaging Industry

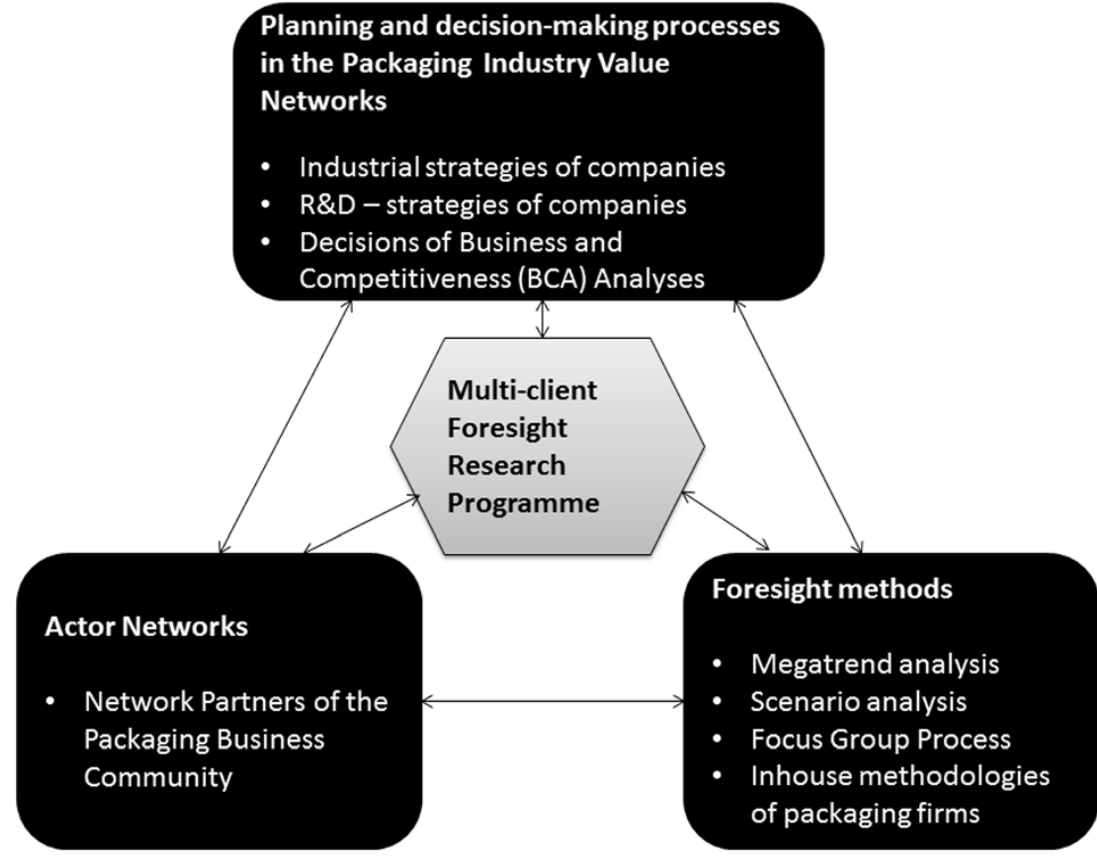

they should aim to sketch possible futures within the boundaries of plausible developments. They should be built on an analysis of factors - social, political, economic, environmental and technological - that could shape the future environment of a given business, region or policy area. Scenarios are not necessarily just dry, analytical descriptions of possible future outcomes, they could also be creative and compelling enough to engage the imagination. They can challenge assumptions, raise awareness of underlying factors and stimulate participants into fresh thinking about what could happen and what it would mean for them [33].

Scenarios that are based on contrasting storylines can be used as a tool to explore the different ways in which the future may develop. Scenario methods can be divided into several groups depending on their output, process, starting point etc. One suggested categorization is [8]:

- Quantitative vs qualitative

- Exploratory vs normative

- Predictive vs open

- Reliance on creativity vs reliance on evidence, and

- Forecasting (explorative) vs. backcasting (normative) scenarios.

Another categorization method is based on the nature of the object studied [5]:

- Low uncertainty, predictive

- Forecasts, projections

- What-if analysis;
- High uncertainty, explorative

- External

- Strategic;

- Normative, backcasting

- Preserving

- Transforming.

In this project a qualitative research approach has been chosen and the uncertainty and turbulence of business environment is relatively high, hence primarily explorative scenarios are used both as input and output. The chosen scenario approach is open and reliance is placed on creativity. The selected high level scenarios used as input explore e.g. societal, land use, social lifestyle, sustainability, technology and demography changes, and they have been used as a starting point for further analysis to evaluate potential packaging implications. These implications are the main output of the project and they could be viewed as explorative "mini-scenarios" regarding a particular aspect of future packaging. As an example, one high level explorative scenario is scarce resources, which when explored at the lower packaging level may imply a scenario of leaner, more resource-efficient packaging.

Workshops/focus groups, with invited packaging and other experts, users and members of the Private Owners' Association Packforsk explored packaging implications of trends and drivers and discussed results. Focus group methodology 
includes group discussions organized to explore a specific set of issues. The group is focused through some kind of collective activity such as viewing a film, examining a message or simply debating a particular set of questions [14]. Crucially, focus groups are distinguished from the broader category of group interviews by the explicit use of the group interaction as research data [13].

A typical focus group session concentrates on: (1) gathering opinions, beliefs and attitudes about issues of interest to the topic or theme, (2) testing assumptions, (3) encouraging discussion about a particular topic, (4) building excitement from spontaneous combination of participants' comments and (5) providing an opportunity to learn more about a topic or issue. The focus groups organized in this study are based on respondent moderator and client participant models. Respondent moderator focus group is one where only one of the respondents is asked to act as the moderator temporarily. Client participant focus groups are groups where one or more client representatives participate in the discussion, either covertly or overtly $[11,16,17]$.

Three focus group sessions were conducted between October 2010 and September 2011. The total numbers of participants were 46, whereof:

- 17 Innventia researchers \& managers;

- 7 packaging users;

- 6 packaging \& packaging material suppliers;

- 6 professors and researchers from universities;

- 3 representatives from Private Owners' Association Packforsk;

- 3 packaging press and exhibition organizers;

- 2 retailers; and

- 2 representatives of other packaging associations.

The stakeholder structure of the focus groups represented the European professional packaging business community, especially packaging industries, the academia and users of packaging products and services. The participants came from different European countries. Although a majority of them were Swedish, most of them represented international organizations with main business outside Sweden, primarily in the EU.

The general focus issue was packaging implications, challenges and opportunities in the light of general foresight studies of societal and business development. These topics were elaborated in moderated discussions. To facilitate the discussion, views on specific themes were presented during the sessions by external speakers, e.g. (1) Energy outlook, (2) Packaging value adding strategies for profitability, (3) Packaging system innovation, (4) Packaging sustainability, (5) Reusable and recyclable packaging, (6) Raw material availability, (7) Price trend outlook and (8) Retail perspectives on packaging. The first theme was an energy outlook in the context of the new EU 2020 energy policy being developed [7]. Subsequent themes were decided as part of the research process in the focus group discussions, i.e. the themes themselves represent an outcome of the project, indicating potentially relevant future packaging impact areas.

This kind of thematic grouping helped facilitators and members of focus group sessions in their discussions and dialogues.

The research process can be summarized in the following steps:

1. Selection of high level future scenarios to use as starting points in the focus group sessions

2. Thematic focus group sessions to explore potential packaging implications and scenarios based on high level scenarios, and

3. Concluding summary and analysis of results.

\section{Megatrend analyses and results}

To reflect the globalized world today, a global and European perspective has been one criterion to select relevant foresight studies containing high level scenarios to use as starting point to explore potential packaging implications. The studies/scenarios should also have been published by reputable organizations and have involved a diverse range of researchers to obtain a wide perspective with a scope far beyond the packaging sector. To the largest extent possible, the studies should also be scientific, pragmatic, transparent and contain references to and review other foresight and research studies.

The global megatrends presented below are taken from an Australian research report [12]. This report is based on analyses of over 100 trends contributed by over 40 scientists and business development staff across the CSIRO organization. In the report [12], 19 megatrends were identified and these were grouped, synthesized and reviewed to define five interlinked megatrends.

Megatrend 1: more from less: a world of limited resources

The world has finite natural resources which are being consumed rapidly. At the same time population growth and economic growth are creating increased demand for dwindling resources. Humanity is responding via the invention of ways to extract more value from fewer and less resources. Coming decades will see an imperative for environmental efficiency. There will be new technologies, new government regulations and new markets. 
Resulting potential key packaging implications identified in analysis and workshops:

- Packaging to reduce (food) waste (e.g. fully emptiable, multi-packs, re-closable, smaller size etc.).

- Improved product protection and barriers to reduce (food) loss, waste and extend shelf life.

- Packaging designed for recovery, and a significant part of the raw materials from recycled materials.

- Competition for material for other uses (e.g. bio-energy). Material and energy scarcity can increase prices.

- More people and income growth-higher consumption and packaging demand.

- Lean and sustainable packaging.

All these implications are strategic and visionary challenges for companies and corporations in the packaging industry.

Megatrend 2: a personal touch: personalization of services

Over the past century countries throughout the OECD have experienced growth in the services sector. In Australia a century ago, the services sector contributed to $30 \%$ of gross domestic product (GDP). Today the services sector represents over $70 \%$ of the economy. Societies are making adjustments to this shift in economic activity. This gives rise to a megatrend, which will play out over coming decades, relating to the personalization of services. Personalization involves innovative means of understanding, and supplying, the intimate needs of individual customers en masse.

Resulting potential key packaging implications identified in analysis and workshops:

- Added value by packaging realized through e.g. smart packaging solutions.

- Packaging innovation for healthy and nutritional food.

- Good design to provide a good packaging-user interface and bridge the gap between user expectations and material performance.

- Consumption of services instead of goods can require development of new business models. Packaging as a materialized service

Megatrend 3: on the move: urbanization and increased mobility

People of today are more mobile than ever before. They are changing jobs more often, moving house more often and travelling around cities, countries and the globe more often. This is having a profound impact on people's lifestyles, housing needs, transportation needs and employment markets. One important aspect of mobility is the rapid pace of urbanization throughout Asia, Africa and the Middle East. In 1950 around $30 \%$ of the world's population lived in urban areas. Today, roughly $50 \%$ of the world's population, live in urban areas, and by 2050 this will have increased to $70 \%$.

Resulting potential key packaging implications identified in analysis and workshops:

- Higher demands on packaging logistics efficiency. This could also mean higher barrier requirements for longer shelf life.

- Packaging to enable a mobile lifestyle. In addition, recycling infrastructure has to be established for mobile consumption.

- Urbanization may pave the way for more efficient production and distribution.

- Integrated waste management solutions required.

Megatrend 4: divergent demographics: older, hungry and more demanding

Global, national and local communities are heading in divergent and often conflicting demographic directions. People living in wealthy countries face an ageing population and shrinking workforce. They face diet and lifestyle related health problems with rising rates of obese and overweight people. In contrast the majority of the world's poor face high fertility rates, rapid population growth and high underemployment rates. Developing nations are confronting food security threats highlighted through recent food price volatility.

Into the future hundreds of millions of people will escape from poverty into the middle classes. Many of these people will live in India and China. The new middle class will demand new products and services. Whilst living standards improve there may also emerge environmental challenges of increased consumption of energy, water and raw materials and increased production of waste. The divergent demographics megatrend captures demographic, health and food consumption trends. Governments will be challenged with policy tensions between the needs of the old (e.g. health) versus the needs of the young (e.g. education). There will also be ongoing tension relating to the world's unequal distribution of wealth.

Resulting potential key packaging implications identified in analysis and workshops:

- Universal packaging design that can be handled by everyone.

- A growing prosperous middle class will increase their consumption of goods and packaging

- Increasing demand for healthy and functional food. 
Megatrend 5: i -world: digital and natural convergence

Over the last 20 years the globe has seen rapid growth in Internet usage accompanied by a skyrocketing number of connected devices. As the functionality of the Internet increases, this trend points towards a convergence between the natural and its digital counterpart as social interactions, information systems, transactions and sensory systems are replicated on the Internet.

Resulting potential key packaging implications identified in analysis and workshops:

- Packaging can be a link to the digital world and become a time saving provider.

- Physical (packed) products sometimes replaced by virtual products.

- Electronic tagging increasing.

- Higher importance of IPR issues for packaging and product designs.

\section{Megatrend cross cutting topics}

Topic 1: land use

Land use is a particular issue related to Megatrend 1, 3 and 4, i.e. the need to make more from less, demography and urbanization. Land Use Futures Project [32] concludes that land is one of the greatest assets and that its future use will primarily be influenced by the following drivers:

1. Demographic change

Significant increase in the demand for land for housing, recreation, transport, water, food and energy

Uneven distribution of demographic change in different regions

2. Economic growth and changing global economic conditions

Urbanization

3. Climate change

Land use for bio-energy

4. New technologies

Better productivity in agriculture and industry

5. Societal preferences and attitudes

6. The policy and regulatory environment.

Analysis and workshops concluded that the potential impact on packaging may follow from many dimensions. Land use and infrastructure issues such as urbanization and transport systems will strongly influence the demands on packaging in the value chain. Land use for forestry and agriculture will alter the availability of renewable packaging materials and energy.
A special challenge is to feed a growing global population. Packaging industries could have a key role in preventing food loss and improving food security in the world.

Topic 2: sustainable cities

Design and implementation of future sustainable cities are linked to all Megatrends 1-5 as well as land use and climate change. "Can sustainable cities meet the climate challenges?" is a key question elaborated in a research report [10]. Its starting point is that half of the world's population lives in cities and the proportion is growing. Cities account for an even larger share of world greenhouse gas emissions and energy consumption. Need and demand on sustainable solutions for urban development and growth will grow substantially over the next few decades. Urban shift towards greater sustainability is often a difficult process which places new, high requirements for interaction. According to the report, the ability of firms to deliver solutions that integrate various activities will be important.

The report states that sustainable cities are driven mainly by two trends:

- Urbanization where people are moving to the cities where growth is generated

- Local and global environmental and climate challenges

Among others, the environmental challenges to be addressed are exploitation of land, energy and water supply, waste management and traffic. Despite the big challenges associated with urbanization, there is good ground for optimism according to the report. Dense settlements, construction of new houses and high concentration of the population are factors that can enable rationalization, higher efficiency, planning, integration and economies of scale in a way that is not possible in rural areas. Urbanization can therefore be seen to function as a set of threats, challenges and enablers.

Analysis and workshops indicate that, from a packaging perspective, the sustainability of cities can be highly influenced. Lean packaging solutions are essential for sustainable drinking water supply in many cities. The recovery systems for packaging should be an integrated part of waste management systems and an important source of material and energy. A zero waste society is an even more far-reaching vision adopted by some cities and regions. Packaging can be anticipated as an essential component in the implementation of solutions to move towards zero waste.

Packaging clearly influences efficiency in logistics, handling and distribution, and is an essential component in the necessary stronger de-coupling of production and consumption which is one core aspect of urbanization. Good packaging will reduce the environmental impacts of production, distribution and consumption. Packaging is also important in the social dimension of sustainability, influencing the work 
environment for many people as well as quality of everyday (city) life. Packaging is also a pre-requisite for the trade of practically all goods and hence a key factor for economic growth.

\section{Topic 3: sustainable packaging}

Sustainable packaging is an issue cutting across the megatrends, e.g. economically with all Megatrends 1-5, environmentally with Megatrend 1, 3 and 5, and socially with Megatrends 2-5. It is also closely linked to sustainable cities and sustainable society. Whether sustainable packaging is a threat or an opportunity for the packaging industry has been addressed in a study, where two primary questions were addressed [25]:

- In the light of over capacity, low prices and high raw material costs, should sustainable packaging be a top concern for the packaging industry?

- Will sustainable packaging have a real and lasting impact on packaging products and how the industry does business?

The following key findings were made in the study:

- The pressure for more sustainable packaging will increase.

- The industry needs to be more proactive in defining sustainable packaging. Historically the packaging sector has been in reactive mode. The sustainability agenda has been set by retailers, consumer groups and governmental bodies.

- The industry needs to promote the value and importance of packaging. It is a popular misconception that packaging is wasteful and environmentally harmful.

- The industry needs to communicate the modest direct contribution of packaging to the environmental footprint of packed goods and the success already achieved in reducing the environmental impact of packaging.

It was concluded in the focus group workshops that a key lesson to be learned from the study [25] is that sustainable packaging and packaging to support sustainability at a higher level (product, business, value chain etc.) offers opportunities for the industry. The study also points at the possibilities to proactively shape the future of (sustainable) packaging.

\section{Summary of opportunities and threats}

In Table 1 key opportunities and threats observed in this foresight study are reported.
Table 1 informs in a comprehensive way about key opportunities and emerging threats of the European packaging industry. Every client was able to make their own part of strengths and weaknesses analyses. In this way the study was linked to conventional SWOT analysis and to possible action scenario analyses of the multi-client community.

\section{Discussion and conclusions}

The chosen research approach was found useful in exploring potential impact of emerging megatrends and trends in the multi-client environment characteristic of the packaging industry. In the European packaging industry, various industrial stakeholders have participated and worked together in order to understand the logic of future supply-chain and value networks. It was concluded that trends and changes in the environment will affect packaging and can mean both threats and opportunities for the industry in the future. When the mature markets growth rate is shrinking, the perspectives may have to be broadened. Opportunities are often found in the emerging markets, and packaging is moving towards a more international market. However, there are still big variations within the emerging markets, where many people are still outside the "well developed economic sectors". In countries such as China, the economic growth gives large potential for the packaging industry. An obstacle to growth is however often a lack of raw materials. The Packaging 2020 study [13] further explores differences in preferences and demands between emerging markets like India in comparison with more mature markets like Sweden and the US.

It should be underlined that this study was not focused on technology foresight analysis (TFA). The study concentrated more on the global markets and expected market changes.

The development also means that the Chinese packaging suppliers are starting to compete in international and European markets. To stay and become more competitive, packaging producers need to help customers by providing lean solutions, more services and value. A cost saving effect can often be achieved as an outcome of concrete challenging targets for materials reduction in the context of future limited material availability and high price. It was also concluded that materials research needs to progress even further and stretch the limits of what can be achieved. It was concluded that the sector should aim for lean and light packaging materials, but also that all packaging materials have to be recoverable. These results are in line with the findings of earlier studies [34], whereby more recent studies [13] broaden the environmental dimension to stress sustainability aspects, including social and financial dimensions. Sustainability aspects are most often closely linked to the materials used. Material development requires a lot of resources and foresight input was considered 
Table 1 Opportunities and threats. A summary

Clustered Megatrend/ Opportunities Threats

challenge

\begin{tabular}{|c|c|c|}
\hline "More from less" & Product protection & Deepening poverty due to over-exploitation of natural resources \\
\hline & Packaging to reduce (food) waste (e.g. fully emptiable, & Increasing material prices \\
\hline & multi-packs, re-closable, smaller size etc.) & Increasing energy prices \\
\hline & More people - higher food demand & Scarcity of water, energy etc. \\
\hline & Lean packaging & Competition for raw material to other products (including \\
\hline & Support sustainability at a higher level (product, business, & bio-energy) \\
\hline & value chain etc.) & Competition for forest land use to agriculture, housing, \\
\hline & Proactively shape and define sustainability and sustainable & infrastructure etc. \\
\hline & packaging & Climate change affecting material supply \\
\hline & Aseptic packaging as an alternative to cold chains & Too little emphasis on primary function of packaging \\
\hline & Barriers to extend shelf life & and too much emphasis on recovery of packaging. \\
\hline & Supply chain collaboration for better performance & \\
\hline & Packaging for recovery & \\
\hline & Water packaging & \\
\hline "A personal touch" & Packaging - a materialised service & Consumption of services instead of goods \\
\hline & Smart packaging & \\
\hline & Added value by packaging & \\
\hline & Sustainable packaging/packaging to support sustainability & \\
\hline & Bridge gap between end-user and material & \\
\hline & Packaging innovation for healthy and nutritional food & \\
\hline & New business models & \\
\hline "On the move" & Packaging logistics efficiency & Recycling and waste management availability, convenience \\
\hline & Packaging barriers — shelf life & and capacity \\
\hline & Lifestyle enabler & \\
\hline & Integrated waste management solutions & \\
\hline & $\begin{array}{l}\text { Urbanisation can pave the way for more efficient production } \\
\text { and distribution }\end{array}$ & \\
\hline “Divergent & Universal packaging design & \\
\hline demographics" & Growing middle class & \\
\hline & Growing prosperity & \\
\hline & Healthy food & \\
\hline & Functional food & \\
\hline & Reduce food losses & \\
\hline "iWorld" & Smart packaging & Physical products replaced by virtual products \\
\hline & Logistics efficiency & IPR of packaging and product designs \\
\hline & New business models and products & \\
\hline & Tagging & \\
\hline & Packaging as a time saving provider & \\
\hline & Free content-product samples & \\
\hline & Packaging as a link to the digital world & \\
\hline
\end{tabular}

essential to get decisions right in the light of long lead times and large investments.

From a retail perspective, packaging was identified as an important tool to prevent waste and save resources, offering product protection and adequate shelf life. Easy handling, both in the store and in the sorting process for recovery, was emphasized and a good presentation of the product is a central feature of good consumer and retail packaging. Retailers felt a need to improve the packaging skill level and packaging standards especially for their own brands. Cold chains are sometimes used for products which do not require cold preservation. Aseptic packaging in ambient temperatures is sometimes an alternative to energy consuming refrigerated units. The retail related findings are in line with earlier results [34] but more emphasis is here placed on packaging to prevent food waste throughout the value chain as studied in more depth by several authors [see e.g. 30, 35].

Despite the relatively wide base, the workshops/focus groups can be criticized for being too narrow with a biased member selection that impacts the results. As an example, the share of group members with direct and indirect links to the packaging industry is relatively high, and these people may have a personal interest in bringing up and stressing the benefits of packaging but neglecting the negative aspects of packaging. "Green" people with a different set of values and attitudes related to packaging have not been directly represented in the focus groups, and the outcome may have been different if they had been involved. To tackle the problem and 
to get a more balanced view, users of packaging and other experts outside the packaging field have been involved in the workshops.

The packaging contribution to future success in the market place may be considered to be over emphasized and the paper may give the impression that packaging development is the answer to any business problem or opportunity. The research results should however not be interpreted in such a manner. They should rather be used to indicate areas where packaging may contribute to add value and provide differentiated integrated products and services for a dynamic future market. Despite the criticism that can be raised, it is believed that the research approach can be well justified in conjunction with the research purpose, which was to explore the potential opportunities and threats for packaging in a strategic and participatory foresight process, rather than to accurately predict the future packaging developments. The article provides new perspectives to the field, not only analyzing both industry and consumer driven drivers of change, but also discussing driven and identified implications.

Acknowledgments Innventia, RISE and the Private Owners' Association Packforsk are kindly thanked for their financial contribution to the project.

Anders Sörås, Lars A Johansson, Pia Wågberg, and Kennert Johansson are thanked for insights and contribution as workshop moderators.

Open AccessThis article is distributed under the terms of the Creative Commons Attribution License which permits any use, distribution, and reproduction in any medium, provided the original author(s) and the source are credited.

\section{References}

1. Agami N, Omran A, Saleh M, El-Shishiny H (2008) An enhanced approach for trend impact analysis. Technol Forecast Soc Chang 75(9):1439-1450

2. Allee V (2008) Value network analysis and value conversion of tangible and intangible assets. J Intellect Cap 9(1):5-24

3. Anderson P, Tushman M (1990) Technological discontinuities and dominant designs: a cyclical model of technical change. Adm Sci Q 35:604-633

4. Bergek A, Berggren C, Magnusson T (2011) Creative accumulation: integrating new and established technologies in periods of discontinuous change. In: Berggren C, Bergek A, Bengtsson L, Söderlund J, Hobday M (eds) Knowledge integration and innovation. critical challenges facing international technology-based firms. Oxford University Press, Oxford, pp 246-273

5. Börjeson L, Höjer M, Dreborg K, Ekvall T, Finnveden G (2006) Scenario types and techniques: towards a user's guide. Futures 38 : 723-739

6. Chia R (2008) Enhancing entrepreneurial learning though peripheral vision. In: Harrison R, Leitch C (eds) Entrepreneurial learning: conceptual frameworks and applications. Routledge, London, pp $27-43$

7. EU 2020 Energy Policy Public consultation (2010) http://ec.europa.eu/ energy/strategies/consultations/2010_07_02_energy_strategy en.htm
8. EU JRC (2014) Foresight guide, For-Learn. The FOR-LEARN Online Foresight Guide. Web: http://forlearn.jrc.ec.europa.eu/guide/ 4 methodology/meth_classification.htm: 12-10

9. European Commission (2002) Practical Guide to Regional Foresight in the UNITED KINGDOM. Editorial team Ian Miles and Michael Keenan. Office for Official Publications of the European Communities, Luxembourg

10. Frenning K, Ståhl B (2011) Framtid med växtverk-Kan hållbara städer möta klimatutmaningarna? Vinnova Analys VA 2011:2, February, VINNOVA, Stockholm

11. Greenbaum T (2000) Moderating focus groups. Sage, Thousand Oaks

12. Hajkowicz S, Moody J (2010) CSIRO. Our future world, an analysis of global trends, shocks and scenarios, Draft document, March 2010, Web: www.csiro.au

13. Innventia Global Outlook Packaging 2020 (2013), Innventia Report No. 387, Stockholm

14. Kitzinger J (1999) Methodology of focus groups: The importance of interaction between research participants. In: Bryman A, Burgess R (eds) Qualitative research, Vol. II. SAGE Publications, London

15. Loveridge D (2009) Foresight: the art and science of anticipating the future. Routledge, New York

16. Merton R, Kendall P (1946) The focused interview. Am J Sociol 51: $541-557$

17. Morgan D (1988) Focus groups as qualitative research. Qualitative research methods 16. Sage Publications, Thousand Oaks

18. Olsmats C (1997) Packa Futura 1997, Packforsk report, Kista, Pira International, Into the Millenium-packaging. Pira International, Leatherhead

19. Olsmats C (1999) Tomorrow's consumer and new business structures-implications for packaging, Packa Futura 1999, Packforsk report, Kista

20. Olsmats C (2001) Drivkrafter i omvärlden och deras konsekvenser för framtida logistik-, marknads- och miljökrav på förpackningssystemet, Thesis for the degree of Licentiate in Engineering, Industrial Economics and Management, Faculty of Chemical Engineering, Åbo Akademi University, Finland

21. Olsmats C (ed) (2001) Packa futura 1996-The packaging market, Packforsk report, Kista

22. Olsmats C (2001) Packaging foresight—Packa Futura 2001, Packforsk report, Kista

23. Olsmats C (2002) The business mission of packaging — packaging as a strategic tool for business development towards the future, Doctoral thesis in Industrial Economics and Management, Åbo Akademi University Press, Åbo

24. Olsmats C, Löfgren C, Lorentzon A, Edholm B Glasenapp A, Sturges M (2011) Packa futura - packaging foresight; global drivers and packaging implications, Backcasting of EU energy policy 2020, Innventia report 312, Kista

25. PriceWaterhouseCoopers (PWC) (2010) Sustainable packaging: threat or opportunity? Web: www.pwc.com

26. Schoemaker P (1992) Integrating scenarios into strategic decision planning at Royal Dutch/Shell. Plan Rev 20(3):41-46

27. Schoemaker P (1993) Multiple scenario development: its conceptual and behavioral foundation. Strateg Manag J 14(1993): 193-213

28. Schoemaker P, van der Heijden CAJM (1993) Strategic planning at Royal Dutch/Shell. J Strateg Chang 2(1993):157-171

29. Schwarz J (2007) Competitive intelligence: a field for futurists? Futur Res Q 23(1):55-65

30. Silvenius F, Grönman K, Katajajuuri J, Soukka R, Koivupuro H, Virtanen Y (2013). The role of household food waste in comparing environmental impacts of packaging alternatives. Packaging Technology and Science

31. Sörås A, Olsmats C (1994) The packaging market of the 90-teesdriving forces, consequence analysis and statistics, Packforsk Report, Kista 
32. The Government Office for Science (2010) Foresight land use futures project. Executive Summary, London

33. Wack P (1985) Scenarios: uncharted waters ahead. Harv Bus Rev 63: 73-89

34. Waite N (2005) The future of global packaging. Pira International Ltd/World Packaging Organisation, Leatherhead
35. Williams H, Wikstrom F, Otterbring T, Lofgren M, Gustafsson A (2012) Reasons for household food waste with special attention to packaging. J Clean Prod 24:141-148

36. WPO - World Packaging Organisation/PIRA International Ltd (2008) Market Statistics and Future Trends in Global Packaging, www.worldpackaging.org 